\title{
The human science
}

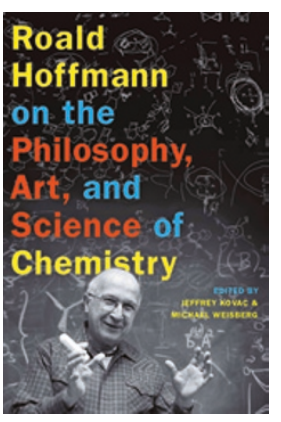

\author{
Roald Hoffmann \\ on the Philosophy, \\ Art and Science of \\ Chemistry
}

Edited by Jeffrey Kovac and Michael Weisberg

OXFORD UNIV. PRESS;

2012. 448 PP $€ 22.50$

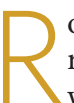
oald Hoffmann is a member of that rare species; a Nobel Prize-winner who has not only made lasting contributions to his discipline but who is also capable of drawing remarkably fertile and wide-ranging connections between chemistry and virtually every other aspect of the natural and human worlds. This book is a compendium of Hoffmann's writings (collected and edited by Kovac and Weisburg) in which he explores chemistry's relationship with fields as diverse as art, poetry, ethics, engineering and philosophy.

The essays are drawn from many sources, but most prominently from his articles in Angewandte Chemie and his regular columns in American Scientist. Some of them are co-authored with other scientists, artists and educators. The book is divided into five sections; chemistry and philosophy, the chemical literature, art and chemistry, chemical education and ethics. Quotations from poets, writers and philosophers are sprinkled throughout the writings. The essays marvellously illuminate the versatility of chemistry in intersecting with a multitude of scientific, artistic and ethical domains.

The varied scope of the book means it is difficult to categorize as a whole, but there are a few consistent undercurrents. One of these is Hoffmann's gentle but spirited critique of reductionism that rejects chemistry's strict reduction to physics. Molecules are made from atoms, but as Hoffmann tells us, they are much more than the sum of their constituent parts. Chemical concepts like electronegativity and hybridization have a life of their own, a utility and relevance that goes beyond their roots in physics; they get "frayed at their edges" if one tries to define them too precisely. Hoffmann makes the cogent point that in chemistry, explanation and understanding are much more important than increasingly accurate calculations and rigorous reductions to theory. This means that empiricism, intuition or even inspired gut feelings - whatever qualities aid understanding - are all valuable in chemical reasoning.

Chemistry's ability to create novel substances on a prolific scale is a feature that distinguishes it from the other sciences and puts it in the league of the creative arts. But as Hoffmann astutely observes, this creative quality leaves traditional tenets of the philosophy of science ill-equipped to capture the essence of chemistry. A typical chemical synthesis where the goal is to create new forms of matter cannot be easily described by the standard criteria of falsification, hypothesis testing or heuristics laid out by well-known philosophers of science. What's the solution? As Hoffmann pithily puts it, "a rotation in a chemistry lab would have been good for these philosophers", most of whom came from physics or biology.

The chapters on art and the chemistry literature really strike at the core of what makes the discipline special. The variety and function of molecular architectures designed by chemists is contrastingly illustrated, on one hand by a complex, multistep synthesis of the antibiotic primaxin and on the other by a magically self-assembling curiosity, the ferric wheel, made by merely mixing two simple chemicals together. The antibiotic is a paragon of utility; the ferric wheel has no immediate use but its spontaneous formation and structure provide "a spiritual high akin to a Haydn piano trio". To describe these varied constructions in their papers chemists have evolved a special code - a wedged line here, a broken line there. Do some of these depictions constitute art? Hoffmann certainly thinks so, because just like art they abstract the essence of reality in ways that can have creative, even emotional resonance. These ruminations in turn lead to one on molecular beauty, with metrics for defining beauty ranging from symmetry to strict utility.

The other parts of the book are shorter and deal with Hoffmann's views on education and ethics. He sees education and research as inseparable: "the practice of teaching enlarges encounters with a real audience and therefore sharpens the imagined audience one engages in the inner dialogue during the course of research". A particularly useful essay imparts practical lessons to both teachers ("Demonstrate!") and to students ("Rework hand-written notes the very same night"). The book concludes with Hoffmann's thoughts on the ethical responsibility of chemists. He sees a need for green chemistry to become a part of mainstream academia, and he is hopeful that a consideration of the environmental impact of their work will be second nature to future generations of scientists.

One of the strengths of this collection is its appeal to diverse audiences. Scientists and philosophers will benefit from the chapters on chemical synthesis and writing, but artists will be intrigued by the discussion of art and representation, and students and laymen will also find valuable titbits in here; a particularly instructive one deals with the deconstruction of a paper describing the synthesis of an antibody mimic. Ultimately the message of the book is that by having such a direct impact on so many of our daily concerns and intellectual engagements, chemistry firmly establishes itself not just as the "central science" but as the human science.

\section{REVIEWED BY \\ ASHUTOSH S. JOGALEKAR}

Ashutosh (Ash) S. Jogalekar is a molecular modeller working on drug design and discovery in the US. He blogs at The Curious Wavefunction (http://wavefunction.fieldofscience.com)

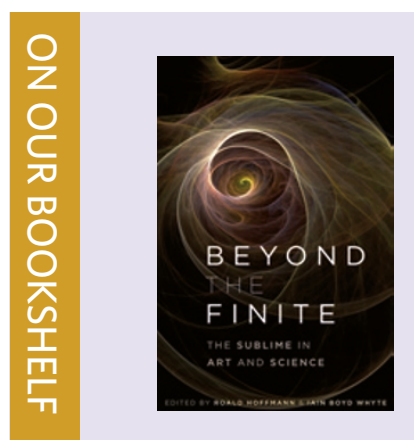

Beyond the Finite: The Sublime in Art and Science Edited by Roald Hoffmann and lain Boyd Whyte OXFORD UNIVERSITY PRESS: 2011. 208PP. £15.99

Nine writers suggest that a shared quest to seek out the sublime can be a fruitful meeting place between the arts and sciences. In Hoffmann's view - he contributes an essay 'On the Sublime in Science' chemistry in particular can achieve this goal because it has moved from analysis to design and synthesis. The book might be an interesting companion to the collection of Hoffmann's essays reviewed above. 